\title{
Two-warehouse system for non-instantaneous deterioration products with promotional effort and inflation over a finite time horizon
}

\author{
M. Palanivel ${ }^{1} \cdot$ S. Priyan $^{1} \cdot$ P. Mala ${ }^{2}$
}

Received: 20 August 2017 / Accepted: 15 November 2017/Published online: 21 November 2017

(C) The Author(s) 2017. This article is an open access publication

\begin{abstract}
In the current global market, organizations use many promotional tools to increase their sales. One such tool is sales teams' initiatives or promotional policies, i.e., free gifts, discounts, packaging, etc. This phenomenon motivates the retailer/or buyer to order a large inventory lot so as to take full benefit of promotional policies. In view of this the present paper considers a two-warehouse (owned and rented) inventory problem for a non-instantaneous deteriorating item with inflation and time value of money over a finite planning horizon. Here, demand depends on the sales team's initiatives and shortages are partially backlogged at a rate dependent on the duration of waiting time up to the arrival of next lot. We design an algorithm to obtain the optimal replenishment strategies. Numerical analysis is also given to show the applicability of the proposed model in real-world two-warehouse inventory problems.
\end{abstract}

Keywords Promotional effort · Two-warehouse · Non-instantaneous · Finite horizon · Inflation

\section{Introduction}

In an oligopolistic supply chain environment, the sales team's initiative/promotional effort plays an important role to boost the sale of items or to speed up the movement of the goods. That is, in recent years, sales team's initiative motivates the customers to buy more items. For example, Wal-Mart frequently encourages the demand for specific types of electronic equipment by offering price discounts. McDonalds frequently offers coupons to attract consumers. Other promotional strategies include free goods, advertisement, and displays. In this direction, Taylor (2002) considered a situation in which the demand is influenced by the sales efforts of retailer. Krishnan et al. (2004) analyzed

\section{S. Priyan}

jaisilpriyan@mepcoeng.ac.in

M. Palanivel

palanimathsgri@gmail.com

P. Mala

ajay16amal13@gmail.com

1 Department of Mathematics, Mepco Schlenk Engineering College, Virudhunagar 626005, Tamilnadu, India

2 Department of Mathematics, Kamaraj College of Engineering \& Technology, Virudhunagar 626001, Tamilnadu, India the coordination of contracts for decentralized supply chains with the promotional efforts of retailers. Tsao and Sheen (2008) developed the inventory model with dynamic pricing, promotion and replenishment policies for a deteriorating item under permissible delay in payments.

Sana (2011) recently discussed an EOQ models for similar products when the demand of the end customers depends on the stock level with selling price and sales teams' initiatives. Sana (2013) formulated an inventory model with sales team's initiatives and stock sensitive demand for a production control system. Cárdenas-Barrón and Sana (2014) proposed a production-inventory model for a two-echelon supply chain when demand is dependent on sales teams' initiatives. Priyan et al. (2015) considered a two-echelon production-inventory system with fuzzy production rate and promotional effort-dependent demand.

In some practical situations, when suppliers offer price discounts for bulk purchases or the products are seasonal, the retailers may purchase more goods than can be stored in his/her own warehouse (OW). Therefore, a rented warehouse $(\mathrm{RW})$ is used to store the excess units over the fixed capacity $W_{1}$ of the own warehouse. Usually, the rented warehouse may charge higher unit holding cost than the own warehouse due to additional cost of maintenance, 
material handling, etc. To reduce the inventory costs, it will be economical to consume the goods of RW at the earliest. Consequently, the firm stores goods in OW before RW, but clears the stocks in RW before OW. Hartely (1976) was the first author to consider the effect of a two-warehouse model in inventory research and developed an inventory model with a RW storage policy. Then Lee and Ma (2000) discussed an optimal inventory policy for deteriorating items with two-warehouse and time-dependent demand. Yang (2004) presented a two-warehouse inventory model with constant deteriorating items, constant demand rate and shortages under inflation. Lee and Hsu (2009) developed a two-warehouse inventory model for deteriorating items with time-dependent demand. Yang (2012) analyzed twowarehouse partial backlogging inventory models with three-parameter Weibull distribution deterioration under inflation. Bhunia et al. (2014) discussed a two-warehouse inventory model for deteriorating items under permissible delay in payment with partial backlogging. Tiwari et al. (2016) developed a two-warehouse inventory model for non-instantaneous deteriorating items and they explored the role of trade credit and inflation on the optimal policy. Xianhao et al. (2017) compared the different dispatching policies in two-warehouse inventory systems for deteriorating items over a finite time horizon.

Deterioration plays a major role in many inventory systems. Deterioration is defined as decay, damage, spoilage, evaporation, obsolescence, pilferage, loss of marginal value of a commodity that results in decreased usefulness. The first attempt to describe the optimal ordering policies for such items was made by Ghare and Schrader (1963). Many researchers (e.g., Tat et al. 2015; Taleizadeh 2014) assumed that the deterioration of the items in inventory starts from the instant of their arrival in stock. In fact, most goods would have a span of maintaining quality or original condition (e.g., vegetables, fruit, fish, meat, etc.), during that period, there is no deterioration occurring. Wu et al. (2006) defined the phenomenon as "non-instantaneous deterioration". In the real world, this type of phenomenon exists commonly such as firsthand vegetables and fruits have a short span of maintaining fresh quality, in which there is almost no spoilage. Afterwards, some of the items will start to decay. For this kind of items, the assumption that the deterioration starts from the instant of arrival in stock may cause retailers to make inappropriate replenishment policies due to overvalue the total annual relevant inventory cost. In this connection, numerous researchers (see Geetha and Uthayakumar 2010; Maihami and Abadi 2012; Dye 2013; Ghoreishi et al. 2014; Palanivel and Uthayakumar 2015; Malik and Singh 2011; Taleizadeh et al. 2015; Mukhopadhyay et al. 2004) designed inventory models for non-instantaneous deteriorating items.
Economic design of an inventory policy for non-instantaneous deteriorating items under permissible delay in payment is developed by Geetha and Uthayakumar (2010). Joint control of inventory and its pricing for noninstantaneous deteriorating items under permissible delay in payments and partial backlogging is designed by Maihami and Abadi (2012). Dye (2013) investigated the effect of preservation technology investment on a noninstantaneous deteriorating inventory model. Ghoreishi et al. (2014) derived an optimal pricing and ordering policy for non-instantaneous deteriorating items under inflation and customer returns. Palanivel and Uthayakumar (2015) recently considered a finite horizon EOQ model for non-instantaneous deteriorating items with probabilistic deterioration and partial backlogging under inflation.

Inflation plays an essential role in the optimal order policy and influences the demand of certain products. As inflation increases, the value of money goes down and erodes the future worth of saving and forces one for more current spending. These spending are on peripherals and luxury items that give rise to demand of these items. As a result, the effect of inflation and time value of the money cannot be ignored for determining the optimal inventory policy. The concept of the inflation should be considered especially for long term investment and forecasting. Buzacott (1975) first demonstrated the EOQ model taking inflation into account. Hou and Lin (2006) developed an EOQ model for deteriorating items with price and stockdependent selling rates under inflation and time value of money. Mishra (2007) has discussed some problems on approximations of functions in banach spaces. Mirzazadeh et al. (2009) analyzed an inventory model under uncertain inflationary conditions with finite production rate, inflation dependent demand rate for deteriorating items and shortages. Thangam and Uthayakumar (2010) studied an inventory model for deteriorating items with inflation induced demand and exponential partial backorders using a discounted cash flow approach. Sarkar and Moon (2011) considered an imperfect production process for time varying demand with inflation and time value of money for an EMQ model. Guria et al. (2013) formulated an inventory policy for an item with inflation induced purchasing price, selling price and demand with immediate part payment. Uthayakumar and Palanivel (2014) developed an inventory model for defective items with trade credit and inflation. Palanivel and Uthayakumar (2016) gave an inventory model with imperfect items, stock-dependent demand and permissible delay in payments under inflation.

For the case of perishable product, the retailer may need to backlog demand to avoid costs due to deterioration. When the shortage occurs, some customers are willing to wait for back order and others would turn to buy from other 
sellers. In this connection, numerous authors (see Dye et al. 2007; Min and Zhou 2009; Tripathy and Pradhan 2010; Taleizadeh and Pentico 2013; Taleizadeh 2014; Palanivel and Uthayakumar 2016; Maihami and Kamalabadi 2012a; b; Taleizadeh and Nematollahi 2014; Taleizadeh et al. 2017; Taleizadeh 2017; Lashgari and Taleizadeh 2016; Palanivel and Uthayakumar 2016) addressed inventory models with backordering under various environments. Inventory model of deteriorating items with time proportional backlogging rate have been developed by Dye et al. (2007). Min and Zhou (2009) derived a perishable inventory model under stock-dependent selling rate and shortage-dependent partial backlogging with capacity constraint. An EOQ model for Weibull deteriorating items with power demand and partial backlogging have been considered by Tripathy and Pradhan (2010). Taleizadeh and Pentico (2013) provided an economic order quantity model with a known price increase and partial backordering. Taleizadeh (2014) gave an EOQ model with partial backordering and advance payments for an evaporating item.

Palanivel and Uthayakumar (2016) recently framed a two-warehouse inventory model for non-instantaneous deteriorating items with partial backlogging and inflation over a finite time horizon. They base their analyses on simplified assumptions such as demand is constant. Today's highly competitive business environment, the managers of business organizations have a lot of pressure to sell products to downstream channel members. Thus nowadays vendors influence their customers with sales teams' initiatives or promotional policies, i.e., free gifts, discounts, delay in payments, packaging, special services and advertising, among others. So the decision-makers require superior knowledge to make the best use of their promotional efforts in order to take optimal decisions in the inventory system. The topic that has separately received considerable attention in the inventory control literature is promotional effort. In this connection, we develop a model that combines the promotional effort extension of the twowarehouse inventory model developed by Palanivel and Uthayakumar (2016). The aim of this study is to provide the optimal time interval and order quantity while minimizing the system total cost so as to make the best use of their promotional efforts. In addition, our model has a new managerial insight that helps a retailer to optimize the replenishment strategies when demand is dependent on sales teams' initiatives.

The rest of the paper is organized as follows: in Notations and assumptions section, the notations and assumptions, which are used throughout this article, are described. In Model Formulation section, the mathematical model to minimize the total annual inventory cost is established. Solution procedure section presents the solution procedure to find the optimal length of time and order quantity. Numerical example is provided in Numerical example section to illustrate the theory and the solution procedure. This is followed by conclusion.

\section{Notations and assumptions}

\section{Notations}

The following notations are used throughout this paper:

A The ordering cost per order

$C_{\mathrm{hr}} \quad$ The holding cost per item in RW

$C_{\text {ho }} \quad$ The holding cost per item in OW, $C_{\mathrm{hr}}>C_{\mathrm{ho}}$

$C_{2} \quad$ The deterioration cost per unit per cycle

$C_{3} \quad$ The shortage cost for backlogged items per unit per cycle

$C_{4} \quad$ The unit cost of lost sales per unit per cycle

$p \quad$ The purchasing cost per unit

$s \quad$ The selling price per unit, with $s>p$

$\mu_{1} \quad$ The life time of the items in OW

$\mu_{2} \quad$ The life time of the items in RW, $\mu_{1}<\mu_{2}$

$\alpha \quad$ The deterioration rate in OW, $0 \leq \alpha<1$

$\beta \quad$ The deterioration rate in $\mathrm{RW}, 0 \leq \beta<1, \alpha>\beta$

$T \quad$ The length of the order cycle

$H \quad$ The planning horizon

$m \quad$ The number of replenishments during planning horizon, $m=H / T$

$W_{1} \quad$ The capacity of the OW

$W_{2} \quad$ The maximum inventory level in RW

$S \quad$ The maximum inventory level per cycle

BI The maximum amount of shortage demand to be backlogged

$Q \quad$ The 2 nd, $3 \mathrm{rd}, \ldots, m_{\mathrm{th}}$ order size

$r \quad$ The discount rate represents the time value of money

$f \quad$ The inflation rate

$R \quad$ The net discount rate of inflation, i.e., $R=r-f$

$q_{\mathrm{r}}(t) \quad$ The inventory level in RW at time $t$

$q_{0}(t) \quad$ The inventory level in OW at time $t$

$q_{\mathrm{s}}(t) \quad$ The negative inventory level at time $t$

$T_{j} \quad$ The total time that elapsed up to and including the $j$ th replenishment cycle $(j=1,2, \ldots, m)$, where $T_{0}=0, T_{1}=T, \ldots, T_{m}=H$

$t_{\mathrm{r}} \quad$ Length of the period during which the inventory level reaches to zero in $\mathrm{RW}$

$t_{\mathrm{j}} \quad$ Time at which the inventory level in OW in the $j$ th replenishment cycle drops to zero $(j=1,2$, .., $m$ )

$T_{j}-t_{j} \quad$ The time period when shortage occurs $(j=1,2$, $\ldots, m)$

$\mathrm{TC}_{\mathrm{F}} \quad$ The total cost for first replenishment cycle 
TC The total cost of the system over a finite planning horizon $H$

\section{Assumptions}

To develop the mathematical model, the following assumptions are being made:

1. There is no replacement or repair of deteriorated items takes place in a given cycle.

2. Deterioration takes place after the life time of items. That is, during the fixed period, the product has no deterioration. After that, it will deteriorate with constant rate.

3. The effects of inflation and time value of money are considered.

4. The rate of demand for the customer $D$ is given by the following expression $D(\rho)=d_{0}+\tau\left(1-\frac{1}{1+\rho}\right)$, where $d_{0}$ is the first part of the demand rate which is independent on the sales teams' initiatives $\rho$. And $\tau$ is a scale parameter of 2 nd part of the demand which varies with the sales teams' initiatives $\rho$. We shall use $D$ and $D(\rho)$ interchangeable in the rest of the paper.

5. The promotional effort cost PEC is an increasing function of the promotional effort/sales teams' initiatives and the basic demand $P E C=c(\rho-1)^{2}\left[\int_{0}^{T} D \mathrm{~d} t\right]^{\gamma}$, where $c$ is the cost per unit effort of the sales teams' initiatives, $c>0$ and $\gamma$ is a constant.

6. Shortages are allowed and partially backlogged. During stock out period, the backlogging rate is a variable and is dependent on the length of the waiting time for the next replenishment. So the backlogging rate for negative inventory is, $B(t)=\frac{1}{1+\delta(T-t)}$, where $\delta$ is a backlogging parameter $0 \leq \delta \leq 1$ and $(T-t)$ is waiting time $\left(t_{j} \leq t \leq T\right),(j=1,2, \ldots, m)$. The remaining fraction $(1-B(t))$ is lost.

7. The OW has limited capacity of $W_{1}$ units and the RW has unlimited capacity. For economic reasons, the items of RW are consumed first and next the items of OW.

\section{Model formulation}

Suppose that the planning horizon $H$ is divided into $m$ equal parts of length $T=H / m$. Hence the reorder times over the planning horizon $H$ are $T_{j}=j T(j=0,1,2, \ldots$, $m$ ). When the inventory is positive, demand rate is constant, whereas for negative inventory, the demand is partially backlogged. The period for which there is noshortage in each interval $[j T,(j+1) T]$ is a fraction of the scheduling period $T$ and is equal to $k T(0<k<1)$. Shortages occur at time $t_{j}=(k+j-1) T,(j=1,2, \ldots$, $m)$ and are build up until time $t=j T(j=1,2, \ldots, m)$ before they are backordered. This model is demonstrated in Fig. 1. The first replenishment lot size of $S$ which is replenished at $T_{0}=0 . W_{1}$ units are kept in OW and the rest is stored in RW. The items of OW are consumed only after consuming the goods kept in RW.

In the $\mathrm{RW}$, during the time interval $\left[0, \mu_{2}\right]$, the inventory level is decreasing only due to demand rate and the inventory level is dropping to zero owing to demand and deterioration during the time interval $\left[\mu_{2}, t_{r}\right]$. In OW, during the time interval $\left[0, \mu_{1}\right]$, there is no change in the inventory level. However, the inventory $W_{1}$ decreases during $\left[\mu_{1}, t_{r}\right]$ due to deterioration only, but during $\left[t_{r}, t_{1}\right]$, the inventory is depleted due to both demand and deterioration. By the time $t_{1}$, both warehouses are empty. Finally, during the interval $\left[t_{1}, T\right]$, shortages occur and are accumulated until $t=T_{1}$ before they are partially backlogged.

Based on the above description, during the time interval $\left[0, \mu_{2}\right]$, the inventory level in RW is decreasing only due to demand rate and the differential equation representing the inventory status is given by

$\frac{\mathrm{d} q_{\mathrm{r}}(t)}{\mathrm{d} t}=-D, \quad 0 \leq t \leq \mu_{2}$.

With the condition $q_{\mathrm{r}}(0)=W_{2}$, the solution of Eq. (1) is $q_{\mathrm{r}}(t)=W_{2}-D t, \quad 0 \leq t \leq \mu_{2}$.

In the second interval $\left[\mu_{2}, t_{r}\right]$ in RW, the inventory level decreases due to demand and deterioration. Thus, the differential equation given below represents the inventory status:

$\frac{\mathrm{d} q_{\mathrm{r}}(t)}{\mathrm{d} t}+\beta q_{\mathrm{r}}(t)=-D, \quad \mu_{2} \leq t \leq t_{\mathrm{r}}$.

With the condition $q_{\mathrm{r}}\left(t_{\mathrm{r}}\right)=0$, we get the solution of Eq. (3) as:

$q_{\mathrm{r}}(t)=\frac{D}{\beta}\left[e^{\beta\left(t_{\mathrm{r}}-t\right)}-1\right], \quad \mu_{2} \leq t \leq t_{\mathrm{r}}$.

Putting $t=\mu_{2}$ in Eqs. (2) and (4), we find the value of $W_{2}$ as

$W_{2}=D\left[\mu_{2}+\frac{e^{\beta\left(t_{\mathrm{r}}-\mu_{2}\right)}-1}{\beta}\right]$.

Substituting Eq. (5) in Eq. (2) we get

$q_{\mathrm{r}}(t)=D\left[\mu_{2}-t+\frac{e^{\beta\left(t_{\mathrm{r}}-\mu_{2}\right)}-1}{\beta}\right], \quad 0 \leq t \leq \mu_{2}$. 


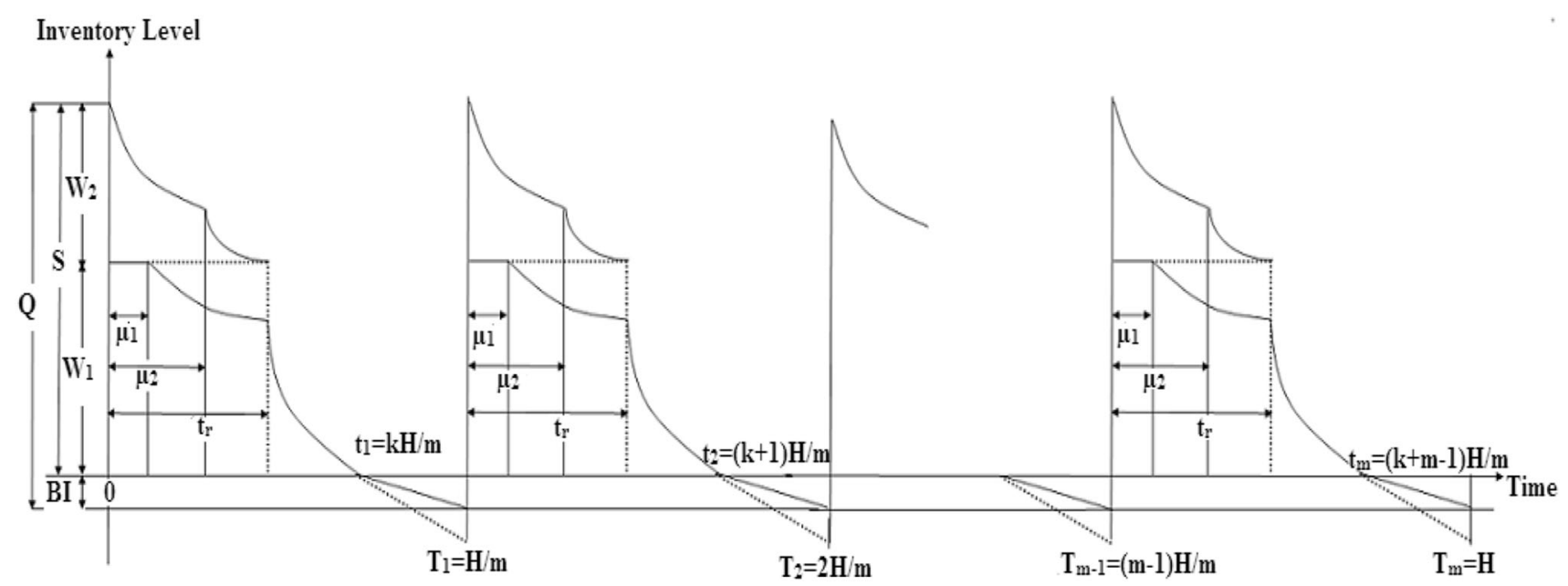

Fig. 1 Graphical representation of the inventory system

In OW, during the time interval $\left[0, \mu_{1}\right]$, there is no change in the inventory level and during $\left[\mu_{1}, t_{r}\right]$ the inventory $W_{1}$ decreases due to deterioration only. Therefore, the rate of change in the inventory is given by

$\frac{\mathrm{d} q_{o}(t)}{\mathrm{d} t}=0, \quad 0 \leq t \leq \mu_{1}$,

$\frac{\mathrm{d} q_{\mathrm{o}}(t)}{\mathrm{d} t}+\alpha q_{\mathrm{o}}(t)=0, \quad \mu_{1} \leq t \leq t_{\mathrm{r}}$.

With the conditions $q_{\mathrm{o}}(0)=W_{1}$ and $\mathrm{q}_{\mathrm{o}}\left(\mu_{1}\right)=\mathrm{W}_{1}$, the solutions of Eqs. (7) and (8) are

$q_{\mathrm{o}}(t)=W_{1}, \quad 0 \leq t \leq \mu_{1}$,

$q_{\mathrm{o}}(t)=W_{1} e^{\alpha\left(\mu_{1}-t\right)}, \quad \mu_{1} \leq t \leq t_{\mathrm{r}}$.

In the interval $\left[t_{\mathrm{r}}, t_{1}\right]$ in $\mathrm{OW}$, the inventory level decreases due to demand and deterioration. Thus, the differential equation is

$\frac{\mathrm{d} q_{o}(t)}{\mathrm{d} t}+\alpha q_{o}(t)=-D, \quad t_{\mathrm{r}} \leq t \leq t_{1}$.

With the condition $q_{\mathrm{o}}\left(t_{1}\right)=0$, we get the solution of Eq. (11) as

$q_{\mathrm{o}}(t)=\frac{D}{\alpha}\left[e^{\alpha\left(t_{1}-t\right)}-1\right], \quad t_{\mathrm{r}} \leq t \leq t_{1}$.

Putting $t=t_{\mathrm{r}}$ in Eqs. (10) and (12), we get

$t_{\mathrm{r}}=t_{1}-\mu_{1}-\frac{1}{\alpha} \ln \left(\frac{W_{1} \alpha}{D}\right)$.

During the interval $\left[t_{1}, T\right]$, shortages occur and the demand is partially backlogged. That is, the inventory level at time $t$ is governed by the following differential equation: $\frac{\mathrm{d} q_{\mathrm{s}}(t)}{\mathrm{d} t}=\frac{-D}{1+\delta(T-t)}, \quad t_{1} \leq t \leq T$.

With the condition $q_{\mathrm{s}}\left(t_{1}\right)=0$, the solution of Eq. (14) is $q_{\mathrm{s}}(t)=D\left(t_{1}-t\right)\left[1-\delta T+\frac{\delta}{2}\left(t_{1}+t\right)\right], \quad t_{1} \leq t \leq T$.

Therefore, the maximum inventory level and maximum amount of shortage demand to be backlogged during the first replenishment cycle are:

$S=W_{1}+D\left[\mu_{2}+\frac{e^{\beta\left(t_{\mathrm{r}}-\mu_{2}\right)}-1}{\beta}\right]$,

$\mathrm{BI}=\frac{\mathrm{DH}(1-k)}{2 m^{2}}[2 m-\delta H(1-k)]$,

respectively, where

$t_{\mathrm{r}}=\frac{k H}{m}-\mu_{1}-\frac{1}{\alpha} \ln \left(\frac{W_{1} \alpha}{D}\right)$.

There are $m$ cycles during the planning horizon. Since, inventory is assumed to start and end at zero, an extra replenishment at $T_{m}=H$ is required to satisfy the backorders of the last cycle in the planning horizon. Therefore, there are $m+1$ replenishments in the entire planning horizon $H$.

The first replenishment lot size is $S$.

The $2 \mathrm{nd}, 3 \mathrm{rd}, \ldots, m$ th replenishment order size is

$Q=S+\mathrm{BI}$.

The last or $(m+1)$ th replenishment lot size is $B I$.

Since replenishment in each cycle is done at the start of each cycle, the present value of ordering cost during the first cycle is

$\mathrm{OC}=A$. 
The holding cost $\mathrm{HC}_{\mathrm{r}}$ for the $\mathrm{RW}$ during the first replenishment cycle is

$$
\begin{aligned}
H C_{\mathrm{r}}= & C_{\mathrm{hr}}\left[\int_{0}^{\mu_{2}} q_{\mathrm{r}}(t) e^{-R t} \mathrm{~d} t+\int_{\mu_{2}}^{t_{r}} q_{\mathrm{r}}(t) e^{-R t} \mathrm{~d} t\right] \\
= & C_{\mathrm{hr}}\left\{\frac{D}{R}\left\{\left(\frac{e^{\beta\left(t_{\mathrm{r}}-\mu_{2}\right)}-1}{\beta}-\frac{1}{R}\right)\left(1-e^{-R \mu_{2}}\right)+\mu_{2}\right\}\right. \\
& \left.+\frac{D}{\beta}\left\{e^{-R t_{\mathrm{r}}}\left(\frac{\beta}{R(\beta+R)}\right)+e^{-R \mu_{2}}\left(\frac{e^{\beta\left(t_{\mathrm{r}}-\mu_{2}\right)}}{\beta+R}-\frac{1}{R}\right)\right\}\right\} .
\end{aligned}
$$

The holding cost $\mathrm{HC}_{\mathrm{o}}$ for the $\mathrm{OW}$ during the first replenishment cycle is

$$
\begin{aligned}
\mathrm{HC}_{\mathrm{o}}= & C_{\mathrm{ho}}\left[\int_{0}^{\mu_{1}} q_{\mathrm{o}}(t) e^{-R t} \mathrm{~d} t+\int_{\mu_{1}}^{t_{\mathrm{r}}} q_{\mathrm{o}}(t) e^{-R t} \mathrm{~d} t+\int_{t_{r}}^{t_{1}} q_{\mathrm{o}}(t) e^{-R t} \mathrm{~d} t\right] \\
= & C_{\mathrm{ho}}\left\{\frac{W_{1}}{R}\left(1 e^{-R \mu_{1}}\right)+\frac{W_{1} e^{\alpha \mu_{1}}}{\alpha+R}\left(e^{-(\alpha+R) \mu_{1}} e^{-(\alpha+R) t_{\mathrm{r}}}\right)\right. \\
& \left.+\frac{D}{\alpha}\left\{e^{-R k H / m}\left(\frac{\alpha}{R(\alpha+R)}\right)+e^{-R t_{r}}\left(\frac{e^{\alpha\left((k H / m)-t_{r}\right)}}{\alpha+R}-\frac{1}{R}\right)\right\}\right\} .
\end{aligned}
$$

The deteriorating cost $\mathrm{DC}_{r}$ for $\mathrm{RW}$ during the first replenishment cycle is

$$
\begin{aligned}
\mathrm{DC}_{\mathrm{r}} & =C_{2} \int_{\mu_{2}}^{t_{\mathrm{r}}} \beta q_{\mathrm{r}}(t) e^{-R t} \mathrm{~d} t \\
& =\mathrm{DC}_{2}\left\{e^{-R t_{\mathrm{r}}}\left(\frac{\beta}{R(\beta+R)}\right)+e^{-R \mu_{2}}\left(\frac{e^{\beta\left(t_{\mathrm{r}}-\mu_{2}\right)}}{\beta+R}-\frac{1}{R}\right)\right\} .
\end{aligned}
$$

The deteriorating cost $\mathrm{DC}_{\mathrm{o}}$ for $\mathrm{OW}$ during the first replenishment cycle is

$$
\begin{aligned}
\mathrm{DC}_{\mathrm{o}}= & C_{2} \alpha\left[\int_{\mu_{1}}^{t_{\mathrm{r}}} q_{\mathrm{o}}(t) e^{-R t} \mathrm{~d} t+\int_{t_{\mathrm{r}}}^{t_{1}} q_{\mathrm{o}}(t) e^{-R t} \mathrm{~d} t\right] \\
= & C_{2} \alpha\left\{\frac{W_{1} e^{\alpha \mu_{1}}}{\alpha+R}\left(e^{-(\alpha+R) \mu_{1}} e^{-(\alpha+R) t_{\mathrm{r}}}\right)\right. \\
& \left.+\frac{D}{\alpha}\left\{e^{-R k H / m}\left(\frac{\alpha}{R(\alpha+R)}\right)+e^{-R t_{\mathrm{r}}}\left(\frac{e^{\alpha\left((k H / m)-t_{\mathrm{r}}\right)}}{\alpha+R}-\frac{1}{R}\right)\right\}\right\} .
\end{aligned}
$$

Total shortage cost SC during the first replenishment cycle is given by

$$
\begin{aligned}
\mathrm{SC} & =-C_{3} \int_{t_{1}}^{T} q_{\mathrm{s}}(t) e^{-R t} \mathrm{~d} t \\
= & \frac{-C_{3} D}{R}\left\{\begin{array}{r}
e^{-R H / m}\left[\frac{k H^{2} \delta}{m^{2}}\left(1-\frac{k}{2}-\frac{m}{\delta H}\right)+\frac{H}{m}\left(1-\frac{\delta H}{2 m}\right)+\frac{1}{R}\left(1+\frac{\delta}{R}\right)\right] \\
\quad \\
+\frac{e^{-R k H / m}}{R}\left[\frac{\delta H}{m}\left(1-k-\frac{m}{H R}\right)-1\right]
\end{array}\right\}
\end{aligned}
$$

The lost sales cost LC during the first replenishment cycle is

$$
\begin{aligned}
\mathrm{LC} & =C_{4} \int_{t_{1}}^{T}\left(1-\frac{1}{1+\delta(T-t)}\right) D e^{-R t} \mathrm{~d} t \\
& =\frac{-C_{4} D \delta}{R^{2}}\left[e^{-R H / m}+e^{-R k H / m}\left(\frac{R H}{m}(1-k)-1\right)\right] .
\end{aligned}
$$

Replenishment is done at $t=0$ and $T$. The present value of purchasing cost PC during the first replenishment cycle is

$$
\begin{aligned}
\mathrm{PC}= & p S+p e^{-R T}(\mathrm{BI}) \\
= & p\left\{W_{1}+D\left[\mu_{2}+\frac{e^{\beta\left(t_{\mathrm{r}}-\mu_{2}\right)}-1}{\beta}\right]\right. \\
& \left.+D e^{-R H / m} \frac{H}{m}(1-k)\left[1+\frac{\delta H}{2 m}(k-1)\right]\right\} .
\end{aligned}
$$

The promotional effort cost PEC for the first replenishment cycle is given by

$\mathrm{PEC}=c(\rho-1)^{2}\left[\int_{0}^{T} D \mathrm{~d} t\right]^{\gamma}=c(\rho-1)^{2}(\mathrm{DT})^{\gamma}$.

Hence, the system inventory total cost $=$ ordering cost + inventory holding cost in RW + inventory holding cost in $\mathrm{OW}+$ deterioration cost in $\mathrm{RW}+$ deterioration cost in OW + shortage cost + lost sales cost + purchasing cost + promotional effort cost. Mathematical expression of the system cost is given below:

$\mathrm{TC}_{F}=\mathrm{OC}+\mathrm{HC}_{\mathrm{r}}+\mathrm{HC}_{\mathrm{o}}+\mathrm{DC}_{\mathrm{r}}+\mathrm{DC}_{\mathrm{o}}+\mathrm{SC}+\mathrm{LC}+\mathrm{PC}$ + PEC.

So, the present value of total cost of the system over a finite planning horizon $H$ is

$$
\begin{aligned}
\mathrm{TC}(\rho, m, k) & =\sum_{j=0}^{m-1} \mathrm{TC}_{F} e^{-R j T}+A e^{-R H} \\
& =\mathrm{TC}_{F}\left(\frac{1-e^{-R H}}{1-e^{-R H / m}}\right)+A e^{-R H},
\end{aligned}
$$

where $T=H / m$ and $\mathrm{TC}_{F}$ is derived by substituting Eqs. (20) to (28) in Eq. (29). 
On simplification, we get

$$
\begin{aligned}
& \mathrm{TC}(\rho, m, k)=A e^{-R H}+G \\
& \left\{A+c(\rho-1)^{2}(\mathrm{DT})^{\gamma}+\frac{\mathrm{C}_{\mathrm{hr}} \mathrm{D}}{\mathrm{R}}\left\{\left(\frac{\mathrm{e}^{\beta\left(\mathrm{t}_{\mathrm{r}}-\mu_{2}\right)}-1}{\beta}-\frac{1}{\mathrm{R}}\right)\left(1-\mathrm{e}^{-\mathrm{R} \mu_{2}}\right)+\mu_{2}\right\}\right. \\
& +\left[\frac{C_{\mathrm{hr}} D}{\beta}+\mathrm{DC}_{2}\right] \times\left\{e^{-R t_{r}}\left(\frac{\beta}{R(\beta+R)}\right)+e^{-R \mu_{2}}\left(\frac{e^{\beta\left(t_{\mathrm{r}}-\mu_{2}\right)}}{\beta+R}-\frac{1}{R}\right)\right\} \\
& +\frac{C_{\mathrm{ho}} W_{1}}{R}\left[1-e^{-R \mu_{1}}\right] \\
& +\left[C_{\mathrm{ho}}+C_{2} \alpha\right] \times\left\{\frac{W_{1} e^{\alpha \mu_{1}}}{\alpha+R}\left(e^{-(\alpha+R) \mu_{1}}-e^{-(\alpha+R) t_{r}}\right)\right. \\
& \left.+\frac{D}{\alpha}\left\{e^{-R k H / m}\left(\frac{\alpha}{R(\alpha+R)}\right)+e^{-R t_{r}}\left(\frac{e^{\alpha\left((k H / m)-t_{\mathrm{r}}\right)}}{\alpha+R}-\frac{1}{R}\right)\right\}\right\} \\
& -\frac{C_{3} D}{R}\left\{e^{-R H / m}\left[\frac{k H^{2} \delta}{m^{2}}\left(1-\frac{k}{2}-\frac{m}{\delta H}\right)+\frac{H}{m}\left(1-\frac{\delta H}{2 m}\right)+\frac{1}{R}\left(1+\frac{\delta}{R}\right)\right]\right. \\
& \left.+\frac{e^{-R k H / m}}{R}\left[\frac{\delta H}{m}\left(1-k-\frac{m}{H R}\right)-1\right]\right\}-\frac{C_{4} D \delta}{R^{2}} \\
& \\
& \left.+e^{-R H / m}+e^{-R k H / m}\left(\frac{R H}{m}(1-k)-1\right)\right] \\
& +p\left\{W_{1}+D\left[\mu_{2}+\frac{e^{\beta\left(t_{\mathrm{r}}-\mu_{2}\right)}-1}{\beta}\right]+D e^{-R H / m} \frac{H}{m}(1-k)\right. \\
& \left.+1+\frac{\delta H}{2 m}(k-1)\right]
\end{aligned}
$$

where $G=\left(\frac{1-e^{-R H}}{1-e^{-R H / m}}\right)$.

\section{Solution procedure}

The problem formulated in the previous section appears as nonlinear programming problem. To solve this kind of nonlinear problem, we follow the similar procedure of most of the literature dealing with nonlinear problem. That is, minimize the total relevant cost function $\mathrm{TC}(\rho, m, k)$ over the variables $\rho, m$ and $k$ with classical differential calculus optimization techniques by taking the first partial derivatives of $\operatorname{TC}(\rho, m, k)$ with respect to $k$ only since $\rho$ and $m$ are discrete variables and $k$ is a continuous variable. Then, for a given value of $\rho$ and $m$, the necessary condition for $\mathrm{TC}(\rho, m, k)$ to be minimized is $\operatorname{dTC}(\rho, m, k) / \mathrm{d} k=0$ which gives

$$
\begin{aligned}
& \frac{\mathrm{dTC}(\rho, m, k)}{\mathrm{d} k}=\frac{C_{\mathrm{hr}} e^{\beta\left(t_{\mathrm{r}}-\mu_{2}\right)}}{R}\left[1-e^{-R \mu_{2}}\right]+\left[\frac{C_{\mathrm{hr}}}{\beta}+C_{2}\right] \\
& \times\left[\frac{\beta}{\beta+R}\right] \times\left[e^{\beta t_{\mathrm{r}}} e^{-(\beta+R) \mu_{2}}-e^{-R t_{\mathrm{r}}}\right] \\
& \quad+\left[C_{\mathrm{ho}}+C_{2} \alpha\right] \times\left\{\frac{W_{1} e^{\alpha \mu_{1}} e^{-(\alpha+R) t_{\mathrm{r}}}}{D}\right. \\
& \left.+\frac{1}{\alpha}\left[e^{-R t_{\mathrm{r}}}-\left(\frac{\alpha}{\alpha+R}\right) e^{-R k H / m}-\left(\frac{R}{\alpha+R}\right) e^{\alpha k H / m} e^{-(\alpha+R) t_{\mathrm{r}}}\right]\right\}
\end{aligned}
$$

$$
\begin{aligned}
& +\frac{C_{3} \delta}{R}\left\{\frac{H e^{-R H / m}}{m}\left[k+\frac{m}{\delta H}-1\right]\right\}+C_{4} \delta\left[\frac{(1-k) H e^{-R k H / m}}{m}\right] \\
& +e^{-R k H / m}\left[\frac{H}{m}(1-k)-\frac{1}{\delta}\right] \\
& +p\left\{e^{\beta\left(t_{r}-\mu_{2}\right)}+e^{-R H / m}\left[1+(k-1) \frac{\delta H}{m}\right]\right\}=0 .
\end{aligned}
$$

$$
\begin{aligned}
& \}\}, \frac{\mathrm{d}^{2} \mathrm{TC}(\rho, m, k)}{\mathrm{d} k^{2}}=\frac{G D H^{2}}{m^{2}}\left\{\left[1-e^{-R \mu_{2}}\right]\right. \\
& \times\left[\frac{C_{\mathrm{hr}} \beta e^{\beta\left(t_{\mathrm{r}}-\mu_{2}\right)}}{R}\right]+\left[\beta e^{\beta t_{\mathrm{r}}} e^{-(\beta+R) \mu_{2}}+\mathrm{Re}^{-R t_{\mathrm{r}}}\right] \times\left[\frac{C_{\mathrm{hr}}+C_{2} \beta}{\beta+R}\right] \\
& +\left[C_{\mathrm{ho}}+C_{2} \alpha\right] \times\left\{\frac { R } { \alpha } \left[\left(\frac{R}{\alpha+R}\right) e^{\alpha k H / m} e^{-(\alpha+R) t_{\mathrm{r}}}\right.\right. \\
& \left.+\left(\frac{\alpha}{\alpha+R}\right) e^{-R k H / m}-e^{-R t_{\mathrm{r}}}\right] \\
& \left.-\frac{(\alpha+R) W_{1} e^{\alpha \mu_{1}} e^{-(\alpha+R) t_{\mathrm{r}}}}{D}\right\}+\delta e^{-R k H / m}\left[\frac{C_{3}}{R}+C_{4}\right] \\
& \times\left[\frac{R H}{m}(k-1)-1\right] \\
& +C_{3}\left[\frac{\delta}{R} e^{-R H / m}+e^{-R k H / m}\right] \\
& +p\left[\beta e^{\beta\left(t_{\mathrm{r}}-\mu_{2}\right)}+\delta e^{-R H / m}\right]>0 .
\end{aligned}
$$

Furthermore, Eq. (33) shows that $T C(\rho, m, k)$ is convex with respect to $k$. So, for given positive integers $\rho$ and $m$, the optimal value of $k$ can be obtained from (32).

\section{Computational algorithm}

Step 1 Start with $\rho=0$

Step 2 Set $m=1$

Step 3 Compute $k$ from Eq. (32)

Step 4 Substitute the solution obtained for (32) into (31) to compute the total inventory cost TC

Step 5 Increase $m$ by 1 and repeat steps 3-4 until TC $(\rho$, $m-1, k) \geq \mathrm{TC}(\rho, m, k) \leq \mathrm{TC}(\rho, m+1, k)$

Step $6 \operatorname{Set} \mathrm{TC}\left(\rho, m^{*}, k^{*}\right)=\mathrm{TC}(\rho, m, k)$

Step 7 Increase $\rho$ by 1 and repeat steps $2-6$ until TC $(\rho-1$, $\left.m^{*}, k^{*}\right) \geq \mathrm{TC}\left(\rho, m^{*}, k^{*}\right) \leq \mathrm{TC}\left(\rho+1, m^{*}, k^{*}\right)$

Step 8 Set $\operatorname{TC}\left(\rho^{*}, m^{*}, k^{*}\right)=\operatorname{TC}\left(\rho, m^{*}, k^{*}\right)$ is the optimal solution.

Using the optimal solution procedure described above, we can find the optimal order quantity and maximum inventory levels to be 


$$
\begin{aligned}
W_{2}^{*}= & D\left[\mu_{2}+\frac{e^{\beta\left(t_{\mathrm{r}}-\mu_{2}\right)}-1}{\beta}\right], \\
S^{*}= & W_{1}+D\left[\mu_{2}+\frac{e^{\beta\left(t_{\mathrm{r}}-\mu_{2}\right)}-1}{\beta}\right], \\
Q^{*}= & W_{1}+D\left[\mu_{2}+\frac{e^{\beta\left(t_{\mathrm{r}}-\mu_{2}\right)}-1}{\beta}\right] \\
& +\frac{\operatorname{DH}\left(1-k^{*}\right)}{2 m^{* 2}}\left[2 m^{*}-\delta H\left(1-k^{*}\right)\right],
\end{aligned}
$$

where $t_{\mathrm{r}}=\frac{k^{*} H}{m^{*}}-\mu_{1}-\frac{1}{\alpha} \ln \left(\frac{W_{1} \alpha}{D}\right)$.

\section{Numerical example}

To illustrate the solution procedure, let us solve the following numerical example and the results can be found by applying the computer coding of Matlab 6.5.

Consider an inventory system with the following data: $d_{0}=100$ units; $\tau=50 ; c=2 ; \gamma=1 ; W_{1}=50$ units; $p=\$ 4 ; \quad s=\$ 15 ; \quad A=\$ 150 ; \quad C_{\mathrm{hr}}=\$ 2 ; \quad C_{\mathrm{ho}}=\$ 1.2 ;$ $C_{2}=\$ 1.5 ; \quad C_{3}=\$ 5 ; \quad C_{4}=\$ 10 ; \quad \alpha=0.8 ; \quad \beta=0.2 ;$ $\delta=0.008 ; \quad \mu_{1}=5 / 12$ year; $\mu_{2}=8 / 12$ year; $R=0.2$; $H=20$ years.

Using the solution procedure described above, the optimal values of $\rho, m$ and $k$ are $\rho=1, m^{*}=7$, $k^{*}=0.2805$, respectively, and the minimum total cost TC $\left(\rho^{*}, m^{*}, k^{*}\right)=\$ 7555$. We then have, $T^{*}=H / m^{*}=20 /$ $7=2.8571$ year, $\quad t_{\mathrm{r}}^{*}=0.8014$ year, $t_{1}^{*}=k^{*} \mathrm{H} / \mathrm{m}^{*}-$ $=1.8091$ year, $W_{2}=243$ units, $S=293$ units, $Q^{*}=548$ units.

Moreover, if $\mu_{1}=0$ and $\mu_{2}=0$, this model becomes the instantaneous deteriorating item case, and the optimal values of $\rho, m$ and $k$ are $\rho=1, m^{*}=6, k^{*}=0.2529$, respectively. Furthermore, $\quad T^{*}=3.3333$ year, $t_{\mathrm{r}}^{*}=0.8432$ year, $t_{1}^{*}=2.2675$ year, $W_{2}=358$ units, $S=408$ units, $Q^{*}=716$ units and the minimum total cost $\mathrm{TC}\left(\rho^{*}, \mathrm{~m}^{*}, \mathrm{k}^{*}\right)=\$ 9229$.

\section{Managerial insights}

There are some interesting managerial implications in the above analyses. We make the following observations:

- From the comparison of the proposed model with Palanivel and Uthayakumar (2016), we can observe that the optimal decisions of both papers are distinct. That is, the lot size of the proposed model $Q^{*}=548$ units is higher than the lot size $Q^{*}=417$ units of Palanivel and Uthayakumar (2016). This is true in real-life inventor system because promotional tools only for increasing their sales.
- In real-life market, we know that if sales increases then automatically the total cost increase. Our results proved this fact.

- It can be seen that there is a decrease in total cost for the non-instantaneous deteriorating item model. This implies that if the retailer can convert the instantaneously deteriorating items to non-instantaneous deteriorating items by improving stock control, then the total cost per unit time will decrease.

- The computational results of the proposed model show that there is a decrease in total cost from the noninstantaneously deteriorating items compared with instantaneously deteriorating items.

- This model can be adopted in the inventory control of retail business such as food industries, seasonable clothes, domestic goods, automobile, electronic components, etc.

\section{Conclusion}

In oligopolistic marketing environment, the sales team's initiatives/promotional effort plays an important role to inspire the customers to buy more items that result in less inventory cost. In view of this we have complemented the shortcomings in Palanivel and Uthayakumar (2016), and relaxed the improbable assumption that the demand is constant. We developed a two-warehouse inventory model over the finite planning horizon for non-instantaneous deteriorating items with the consideration of sales team's initiative-dependent demand with partial backlogging under inflation and time value of money. Holding costs and deterioration costs are different in OW and RW due to different preservation environments. Mathematical modeling, differential calculus and computational algorithm are employed in this study for optimizing the lot size and setup cost simultaneously. A computer code using the software Matlab is developed to derive the optimal solution of the system.

There are several extensions of this work that could constitute future research related to this field. One immediate probable extension could be to discuss the constant demand to a more generalized demand pattern that fluctuates with price, displayed stock level, time and their combination. Another possible extension of this work may be conducted by considering the trade credit policy. Furthermore, some of major parameter of the model such as demand rate, deterioration rate, holding cost, and ordering cost may be fuzzy variable.

Open Access This article is distributed under the terms of the Creative Commons Attribution 4.0 International License (http://creative commons.org/licenses/by/4.0/), which permits unrestricted use, 
distribution, and reproduction in any medium, provided you give appropriate credit to the original author(s) and the source, provide a link to the Creative Commons license, and indicate if changes were made.

\section{References}

Bhunia AK, Jaggi CK, Sharma A, Sharma R (2014) A two-warehouse inventory model for deteriorating items under permissible delay in payment with partial backlogging. Appl Math Comput 232:1125-1137

Buzacott JA (1975) Economic order quantities with inflation. Oper Res Q 26:553-558

Cárdenas-Barrón LE, Sana SS (2014) A production-inventory model for a two-echelon supply chain when demand is dependent on sales teams' initiatives. Int J Prod Econ 155:249-258

Dye CY (2013) The effect of preservation technology investment on a non-instantaneous deteriorating inventory model. Omega 41:872-880

Dye CY, Ouyang LY, Hsieh TP (2007) Deterministic inventory model for deteriorating items with capacity constraint and timeproportional backlogging rate. Eur J Oper Res 178:789-807

Geetha KV, Uthayakumar R (2010) Economic design of an inventory policy for non-instantaneous deteriorating items under permissible delay in payments. J Comput Appl Math 233:2492-2505

Ghare PM, Schrader GH (1963) A model for exponentially decaying inventory system. Int J Prod Res 21:449-460

Ghoreishi M, Mirzazadeh A, Weber GW (2014) Optimal pricing and ordering policy for non-instantaneous deteriorating items under inflation and customer returns. Optimization 63:1785-1804

Guria A, Das B, Mondal S, Maiti M (2013) Inventory policy for an item with inflation induced purchasing price, selling price and demand with immediate part payment. Appl Math Model 37:240-257

Hartely VR (1976) Operations research-a managerial emphasis. Good Year, California

Hou KL, Lin LC (2006) An EOQ model for deteriorating items with price- and stock-dependent selling rates under inflation and time value of money. Int J Syst Sci 37:1131-1139

Krishnan H, Kapuscinski RK, Butz DA (2004) Coordinating contracts for decentralized supply chain with retailer promotional effect. Manag Sci 50:48-62

Lashgari Mohsen, Taleizadeh AA (2016) An inventory control problem for deteriorating items with back-ordering and financial considerations under two levels of trade credit linked to order quantity. J Ind Manag Optim 12(3):1091-1119

Lee CC, Hsu SL (2009) A two-warehouse production model for deteriorating inventory items with time-dependent demands. Eur J Oper Res 194:700-710

Lee C, Ma C (2000) Optimal inventory policy for deteriorating items with two-warehouse and time-dependent demands. Prod Plan Control 11:689-696

Maihami R, Abadi INK (2012) Joint control of inventory and its pricing for non-instantaneously deteriorating items under permissible delay in payments and partial backlogging. Math Comput Model 55:1722-1733

Maihami R, Kamalabadi IN (2012a) Joint pricing and inventory control for non-instantaneous deteriorating items with partial backlogging and time and price dependent demand. Int J Prod Econ 136:116-122

Maihami R, Kamalabadi IN (2012b) Joint control of inventory and its pricing for non-instantaneously deteriorating items under permissible delay in payments and partial backlogging. Math Comput Model 55(5-6):1722-1733
Malik AK, Singh Y (2011) An inventory model for deteriorating items with soft computing techniques and variable demand. Int $\mathbf{J}$ Soft Comput Eng 1(5):317-321

Min J, Zhou YW (2009) A perishable inventory model under stockdependent selling rate and shortage-dependent partial backlogging with capacity constraint. Int J Syst Sci 40:33-44

Mirzazadeh A, Seyyed Esfahani MM, Fatemi Ghomi SMT (2009) An inventory model under uncertain inflationary conditions, finite production rate and inflation-dependent demand rate for deteriorating items with shortages. Int J Syst Sci 40:21-31

Mishra VN (2007) Some problems on approximations of functions in banach spaces. Ph.D. Thesis Indian Institute of Technology, Roorkee - 247 667, Uttarakhand, India

Mukhopadhyay S, Mukherjee RN, Chaudhuri KS (2004) Joint pricing and ordering policy for a deteriorating inventory. Comput Ind Eng 47(4):339-349

Palanivel M, Uthayakumar R (2015) Finite horizon EOQ model for non-instantaneous deteriorating items with probabilistic deterioration and partial backlogging under inflation. Int J Math Oper Res 8:449-476

Palanivel M, Uthayakumar R (2016a) An inventory model with imperfect items, stock dependent demand and permissible delay in payments under inflation. RAIRO Oper Res 50:473-489

Palanivel M, Uthayakumar R (2016b) Two-warehouse inventory model for non-instantaneous deteriorating items with partial backlogging and inflation over a finite time horizon. Opsearch 53:278-302

Palanivel M, Uthayakumar R (2016c) Two-warehouse inventory model for non-instantaneous deteriorating items with optimal credit period and partial backlogging under inflation. J Control Decis 3(2): 132-150

Priyan S, Palanivel M, Uthayakumar R (2015) Two-echelon production-inventory system with fuzzy production rate and promotional effort dependent demand. J Manag Anal 2:72-92

Sana SS (2011) An EOQ model for salesmen's initiatives, stock and price sensitive demand of similar products - a dynamical system. Appl Math Comput 218:3277-3288

Sana SS (2013) Sales team's initiatives and stock sensitive demanda production control policy. Econ Model 31:783-788

Sarkar B, Moon I (2011) An EPQ model with inflation in an imperfect production system. Appl Math Comput 217:6159-6167

Taleizadeh AA (2014a) An economic order quantity model for deteriorating item in a purchasing system with multiple prepayments. Appl Math Model 38:5357-5366

Taleizadeh AA (2014b) An EOQ model with partial backordering and advance payments for an evaporating item. Int J Prod Econ 155:185-193

Taleizadeh AA (2017) Vendor managed inventory system with partial backordering for evaporating chemical raw material. Sci Iran 24(3):1483-1492

Taleizadeh AA, Nematollahi M (2014) An inventory control problem for deteriorating items with backordering and financial engineering considerations. Appl Math Model 38:93-109

Taleizadeh AA, Pentico DW (2013) An economic order quantity model with a known price increase and partial backordering. Eur J Oper Res 228:516-525

Taleizadeh AA, Noori-daryan M, Cárdenas-Barrón LE (2015) Joint optimization of price, replenishment frequency, replenishment cycle and production rate in vendor managed inventory system with deteriorating items. Int J Prod Econ 159:285-295

Taleizadeh AA, Moshtagh MS, Moon I (2017) Optimal decisions of price, quality, effort level, and return policy in a three-level closed-loop supply chain based on different game theory approaches. Eur J Ind Eng 11(4):486-525

Tat R, Taleizadeh AA, Esmaeili M (2015) Developing economic order quantity model for non- instantaneous deteriorating items 
in vendor-managed inventory (VMI) system. Int J Syst Sci 46:1257-1268

Taylor TA (2002) Supply chain coordination under channel rebates with sales effort effects. Manag Sci 48:992-1007

Thangam A, Uthayakumar R (2010) An inventory model for deteriorating items with inflation induced demand and exponential partial backorders-a discounted cash flow approach. Int J Manag Sci Eng Manag 5:170-174

Tiwari S et al (2016) Impact of trade credit and inflation on retailer's ordering policies for non-instantaneous deteriorating items in a two-warehouse environment. Int J Prod Econ 176:154-169

Tripathy CK, Pradhan LM (2010) An EOQ model for Weibull deteriorating items with power demand and partial backlogging. Int J Contem Math Sci 5:1895-1904

Tsao Y-C, Sheen GJ (2008) Dynamic pricing, promotion and replenishment policies for a deteriorating item under permissible delay in payments. Comput Oper Res 35:62-80
Uthayakumar R, Palanivel M (2014) An inventory model for defective items with trade credit and inflation. Prod Manuf Res 2:355-379

Wu KS, Ouyang LY, Yang CT (2006) An optimal replenishment policy for non-instantaneous deteriorating items with stockdependent demand and partial backlogging. Int $\mathrm{J}$ Prod Econ 101:369-384

Xianhao X, Qingguo B, Mingyuan C (2017) A comparison of different dispatching policies in two-warehouse inventory systems for deteriorating items over a finite time horizon. Appl Math Model 41:359-374

Yang HL (2004) Two-warehouse inventory models for deteriorating items with shortages under inflation. Eur J Oper Res 157:344-356

Yang HL (2012) Two-warehouse partial backlogging inventory models with three-parameter Weibull distribution deterioration under inflation. Int J Prod Econ 138:107-116 